\title{
The primary cilium as a novel extracellular sensor in bone
}

\author{
David A. Hoey ${ }^{1,2,3}{ }^{*}$, Julia C. Chen ${ }^{1}$ and Christopher R. Jacobs ${ }^{1}$ \\ ${ }^{1}$ Department of Biomedical Engineering, Columbia University in the City of New York, New York, NY, USA \\ 2 Department of Anatomy, Royal College of Surgeons in Ireland, Dublin, Ireland \\ ${ }^{3}$ Department of Mechanical, Aeronautical and Biomedical Engineering, Centre for Applied Biomedical Engineering Research, Materials and Surface Science \\ Institute, University of Limerick, Limerick, Ireland
}

\section{Edited by:}

Deborah Mason, Cardiff University, UK

\section{Reviewed by:}

Jan Josef Stepan, Charles University

Faculty of Medicine Prague, Czech

Republic

Carmen Huesa, University of

Edinburgh, UK

\section{${ }^{*}$ Correspondence}

David A. Hoey, Department of

Mechanical, Aeronautical and

Biomedical Engineering, Centre for

Applied Biomedical Engineering

Research, Materials and Surface

Science Institute, University of

Limerick, Limerick, Ireland.

e-mail:david.hoey@ul.ie
Mechanically induced adaptation of bone is required to maintain a healthy skeleton and defects in this process can lead to dramatic changes in bone mass, resulting in bone diseases such as osteoporosis. Therefore, understanding how this process occurs could yield novel therapeutics to treat diseases of excessive bone loss or formation. Over the past decade the primary cilium has emerged as a novel extracellular sensor in bone, being required to transduce changes in the extracellular mechanical environment into biochemical responses regulating bone adaptation. In this review, we introduce the primary cilium as a novel extracellular sensor in bone; discuss the in vitro and in vivo findings of primary cilia based sensing in bone; explore the role of the primary cilium in regulating stem cell osteogenic fate commitment and finish with future directions of research and possible development of cilia targeting therapeutics to treat bone diseases.

\section{Keywords: primary cilium, bone, mechanotransduction, fluid flow, osteocyte, stem cell}

\section{INTRODUCTION}

Bone is an intriguingly sensitive tissue, constantly remodeling and adapting its structure to meet the demands of its environment. This is particularly evident after changes in the physical demands of bone such as in overload and disuse scenarios. The phenomenon of mechanically induced bone adaptation was first proposed over a century ago, where it was hypothesized that stresses in the tissue dictated its architecture (Wolff, 1892). Early investigations determined that the distribution of mass corresponded to the direction of maximum principal stress, allowing the greatest strength to be achieved while minimizing weight and consequently energy usage in locomotion. Mechanically induced adaptation of bone is required to maintain a healthy skeleton and defects in this process can lead to dramatic changes in bone mass such as in osteoporosis. Therefore understanding how this process occurs could yield novel therapeutics to treat diseases of excessive bone loss or formation.

Mechanically induced adaptation of bone is ultimately controlled by the cells residing within the tissue. Osteocytes are the most abundant cell type in bone and by the formation of an interconnected network through the lacunar-canalicular passages, these cells are ideally positioned to monitor the bone mechanical environment and communicate that signal to effector cells such as osteoblasts and osteoclasts (Tatsumi et al., 2007; Jacobs et al., 2010). The application of load to bone is known to generate numerous forms of mechanical stimulation at a cellular level including substrate strain, fluid flow, pressure, and streaming potentials. In vitro analysis of each loading scenario at physiologically relevant levels has highlighted fluid flow as a highly potent stimulus (Rubin and Lanyon, 1984; You et al., 2000). Therefore, much attention has been paid to fluid flow through the lacunar-canalicular network (Price et al., 2011). The application of continuous, pulsatile, and oscillatory fluid flow to bone cells in vitro has been shown to elicit a pro-anabolic and anti-catabolic response (Klein-Nulend et al., 1995; Jacobs et al., 1998; You et al., 2000; Donahue et al., 2003; Kim et al., 2006). However, how these cells transduce this extracellular stimulus into a biochemical bone forming intracellular response remains poorly understood.

There have been numerous potential extracellular sensors proposed and investigated to date (Rubin et al., 2006; Jacobs et al., 2010). Ion channels, integrins and associated proteins (Wang et al., 2007; Litzenberger et al., 2010), connexins (Saunders et al., 2003), and the actin cytoskeleton (Malone et al., 2007b) have all been implicated in bone cell mechanosensation. Due to the complexity of the extracellular mechanical environment in bone, it is very likely that these potential mechanosensors interact with one another, integrating the multiple extracellular signals into one cohesive signal. Recent work has revealed a new potential mechanosensor, the primary cilium, and it is the focus of this review. In this review, we introduce the primary cilium as a novel extracellular sensor (see The Primary Cilium); discuss the in vitro (see In vitro Studies) and in vivo (see In vivo Studies) findings on primary cilia based sensing in mature bone; explore the role of the primary cilium in regulating stem cell osteogenic fate commitment (see Primary Cilia in Osteoprogenitors) and finish with future directions of in vitro (see In vitro Models) and in vivo (see In vivo Models) research and possible development of cilia targeting therapeutics to treat diseases of excessive bone loss or formation (see Potential Cilium Targeted Therapeutics).

\section{THE PRIMARY CILIUM}

A primary cilium is a membrane bound "hair-like" cellular organelle consisting of nine microtubule doublets (axoneme) 
which extends from the circumferentially arranged microtubule triplets of the mother centriole. The ciliary axoneme is separated from the cell cytoplasm by structural features known as alar sheets. This separation creates a ciliary microdomain allowing for specific localization and concentration of receptors, ion channels, and effector proteins (Hoey et al., 2012a). Although originally identified by Ecker (1844) in sea lamprey and shortly after by Zimmerman (1898) in humans, research into the function of primary cilia remained relatively stagnant due to limitations in imaging technology and assumptions of vestigiality (Bloodgood, 2009). Despite Zimmerman's early hypothesis that the cilium may possess sensory characteristics, only within the last two decades, with findings that defects in the cilium directly result in human pathologies, has interest in the primary cilium expanded (Hildebrandt et al., 2011). It is now widely accepted that this solitary, immotile cellular organelle plays numerous pivotal roles, coordinating several signaling pathways, and acts as an extracellular sensor with both chemosensory and mechanosensory capabilities through the localization of receptors and ion channels to the axoneme of the cilium. The sensory roles of the primary cilium have been summarized previously in many excellent reviews and so will not be discussed in detail here (Singla and Reiter, 2006; Veland et al., 2009; Lee et al., 2010). However, a brief description of key findings follows.

Extending into the extracellular milieu, the primary cilium is ideally positioned to act as a sensory organelle. Olfactory sensory neurons localize G protein coupled receptors (GPCRs) to the axoneme of cilium allowing maximum exposure of these receptors to odorant molecules (Krieger et al., 1994). In addition, several downstream regulators of olfactory signaling are also localized to the cilium, which would facilitate an amplification of the initial signal within the ciliary domain (Benton et al., 2006). A similar phenomenon exists in the rod and cone cells of the retina (Elias et al., 2004). Disruption of the primary cilium in both cell types results in defective olfaction and photoreception demonstrating the potent chemosensory role of the primary cilium (Li et al., 1996; Benton et al., 2006). The extracellular location of the cilium not only optimizes chemosensory functions but also perfectly positions the cilium to sense the local extracellular mechanical environment. An extracellular mechanosensory role for the primary cilium was first demonstrated in the kidney. Kidney epithelial cells line the lumen of the tubules, and extend a primary cilium, which has been shown to deflect under luminal fluid flow (Praetorius and Spring, 2001). This deflection of the primary cilium results in a release of intracellular calcium $\left(\mathrm{Ca}^{2+}\right)$ that is dependent upon influx of extracellular $\mathrm{Ca}^{2+}$ through the ciliary localized calcium channel complex polycystin1/2 (PC1/2; Nauli and Zhou, 2004). The epithelial cells lining the intrahepatic bile ducts of the liver (cholangiocytes) are an excellent example of the primary cilium as an extracellular sensor, as the cholangiocyte cilium has demonstrated dual chemo/mechanosensory roles. The ciliary localization of $\mathrm{P}_{2} \mathrm{Y}_{12}$ purinergic receptors enables cilia-mediated sensing of biliary nucleotides (Masyuk et al., 2008). Regarding mechanosensing capabilities, deflection of the cilium under biliary flow, results in an influx of $\mathrm{Ca}^{2+}$ similar to the kidney, but also reduces a forskolin stimulated increase in cAMP signaling (Masyuk et al., 2006). In addition, the primary cilium regulates osmosensation of luminal tonicity by ciliary localization of transient receptor potential vanilloid-4 (TRPV4; Gradilone et al., 2007). Similar mechanosensory roles have been demonstrated in other cell types such as endothelial cells where fluid flow is a critical factor of the extracellular mechanical environment regulating tissue homeostasis (Hierck et al., 2008).

Recent work has begun to explore the potential extracellular sensory capabilities of the primary cilium in musculoskeletal tissues, where the extracellular mechanical environment is more complex. Donnelly et al. (2010) quantified the incidence and orientation of primary cilia in tenocytes in situ using multiphoton microscopy. Cilia were observed on $64 \%$ of tenocytes imaged and were found to align in parallel to the collagen fibers and the long axis of the tendon. Gardner et al. (2011) examined the effect of mechanical stimulation on tendon cilia length and discovered that cilia length increases with stress deprivation and decreases in response to mechanical stimulation. This phenomenon has also been witnessed in kidney epithelia (Besschetnova et al., 2010) and strongly indicates a sensory role for the cilium in tendon tissue. This phenomenon also indicates that the cilium can alter it structure and mechanics to adjust its exposure to the extracellular environment subsequently altering its sensitivity (Besschetnova et al., 2010; Downs et al., 2012; Hoey et al., 2012a). A prominent role for the cilium in cartilage growth and maintenance has also emerged. Connexin 43, NG2 and $\alpha 2, \alpha 3, \beta 1$ integrins have been shown to localize to the primary cilium of chondrocytes (McGlashan et al., 2006; Knight et al., 2009) facilitating direct connections between the cilium and the extracellular matrix. Similar to tenocytes and epithelial cells, chondrocytes also reduce cilia length and incidence in response to mechanical stimulation (McGlashan et al., 2010). Furthermore, Wann et al. (2012) recently demonstrated that the chondrocyte primary cilium was required for mechanotransduction of compressive loading. The growth plate and articular joint surfaces of mouse models of ciliopathies are reduced in size and cellular organization is significantly altered (McGlashan et al., 2007; Kaushik et al., 2009). All of these data strongly implicate the cilium as an extracellular sensor in cartilage. In parallel with the discoveries in other musculoskeletal tissue, progress has been made in understanding the extracellular sensory role of the primary cilium in bone, the matter of which will be the focus of the remainder of this review.

\section{PRIMARY CILIA IN ADULT BONE}

Although the existence of the primary cilium in bone was proven some 40 years ago using electron microscopy (Tonna and Lampen, 1972), the concept that this organelle may play a role in regulating bone homeostasis was proposed only in the last decade by Whitfield (2003). Based on the established flow sensing role of the cilium in the kidney (Praetorius and Spring, 2005) and the importance of fluid flow in regulating bone turnover, it was proposed that the primary cilium may act as a interstitial fluid flow sensor for the osteocyte.

\section{IN VITRO STUDIES}

To investigate the hypothesis that the primary cilium may act as a fluid flow sensor in bone, Xiao et al. (2006) and Malone 
et al. (2007a) first stained for primary cilia in both osteocytes and osteoblasts using immunocytochemistry (see Figure $\mathbf{1}$ for ICC image of a primary cilium). By collecting three-dimensional projections of $z$-stacks, primary cilia were seen extending $4-9 \mu \mathrm{m}$ in length from the apical surface of $\sim 61 \%$ of MC3T3-E1 preosteoblasts and $\sim 62 \%$ of MLO-Y4 osteocyte-like cells imaged. In addition, osteoblasts were imaged under side view and the cells were exposed to a short pulse of $0.03 \mathrm{~Pa}$ of flow induced shear. Under such a regime, the osteoblast primary cilium deflected in a similar fashion to that previously witnessed in kidney epithelial cells (Schwartz et al., 1997) and recoiled upon cessation of flow. These images indicate that bone cell primary cilia possess physical characteristics consistent with flow sensing capabilities.

As mentioned previously, bone cells respond to mechanical stimulation such as fluid flow with a robust increase in osteogenic gene expression and protein secretion. For example, osteoblasts exposed to $1 \mathrm{~h}$ of oscillatory fluid flow induced shear stress respond with a significant threefold increase in Osteopontin (OPN) gene expression (Malone et al., 2007a). However, Malone et al. (2007a) demonstrated that upon removal of the primary cilium by choral hydrate treatment (disrupts the cilia/basal body connection), osteoblasts no longer respond to dynamic fluid flow with this increase in OPN. Furthermore, cells which did not possess a cilium following chloral hydrate treatment, still responded with a 4.4 fold increase in OPN following exposure of $10 \mathrm{nM}$ Vitamin D. Therefore, chloral hydrate treatment did not affect OPN gene expression non-specifically. In addition, the formation of a primary cilium was also inhibited by treatment with siRNA targeting Polaris (intraflagellar transport protein required for ciliogenesis). As with the chloral hydrate treatment, cells which did not possess a primary cilium, did not respond to fluid flow stimulation. A similar trend was also witnessed with PGE2 secretion.

Osteocytes are largely believed to be the coordinators of loading induced bone adaptation in vivo (Tatsumi et al., 2007) through their regulation of osteoclasts (You et al., 2008), osteoblasts (Taylor et al., 2007), and osteoprogenitors (Hoey et al., 2011). Therefore, Malone et al. (2007a) further investigated the role of the primary cilium in osteocyte mechanoregulation. Osteocytes, in response to fluid flow stimulation, respond with a twofold increase in COX-2 gene expression (which is involved in PGE2 production) and also in an increase in the ratio of OPG to RANKL expression which regulates osteoclast differentiation. However, osteocytes which do not possess a primary cilium following siRNA and pharmacological prevention, did not respond to mechanical stimulation. In addition, Hoey et al. (2011) demonstrated that mechanically stimulated osteocytes secrete soluble factors which act in a paracrine manner to enhance osteogenic gene expression in MSCs. This paracrine mechanism is lost with removal of the primary cilium further demonstrating that the primary cilium is required for osteocytes to sense an external mechanical stimulus such as fluid flow resulting in the subsequent signaling to effector cells regulating bone formation.

Primary cilia first emerged as a mechanosensor in the kidney where it is now established that bending of the primary cilium under fluid flow results in an extracellular $\mathrm{Ca}^{2+}$ dependent increase in intracellular $\mathrm{Ca}^{2+}$ and that this mechanism is required for tissue homeostasis (Praetorius and Spring, 2005). As bone cells also respond to fluid flow with an increase in intracellular $\mathrm{Ca}^{2+}$ (Chen et al., 2000; You et al., 2001), this suggested that this response was also cilia dependent. Surprisingly, there was no correlation between ciliated osteoblasts and $\mathrm{Ca}^{2+}$ flux under flow (Malone et al., 2007a). Furthermore, numerous cells which did possess a primary cilium did not respond with a $\mathrm{Ca}^{2+}$ flux and inversely cells which were treated to remove the primary cilium were still capable of responding with an increase in $\mathrm{Ca}^{2+}$. In addition, extracellular $\mathrm{Ca}^{2+}$ was ablated using BAPTA and calcium ion channels were blocked using gadolinium chloride ( $\mathrm{GdCl})$, all of which did not alter flow mediated intracellular $\mathrm{Ca}^{2+}$ flux. The same trend was found in MLO-Y4 osteocytes. These data therefore indicate that cilia-mediated mechanotransduction in bone cells is mechanistically distinct from that in the kidney.

Further work into delineating the cilia-mediated mechanosensing mechanism in bone has uncovered a molecular mechanism involving cyclic adenosine monophosphate (cAMP) and adenylyl cyclase 6 (AC6; Kwon et al., 2010). In response to fluid flow stimulation, osteocytes display a rapid $(2 \mathrm{~min})$, transient decrease in cAMP levels, a response that is necessary for the increase in COX2 expression described previously. Furthermore, upon removal
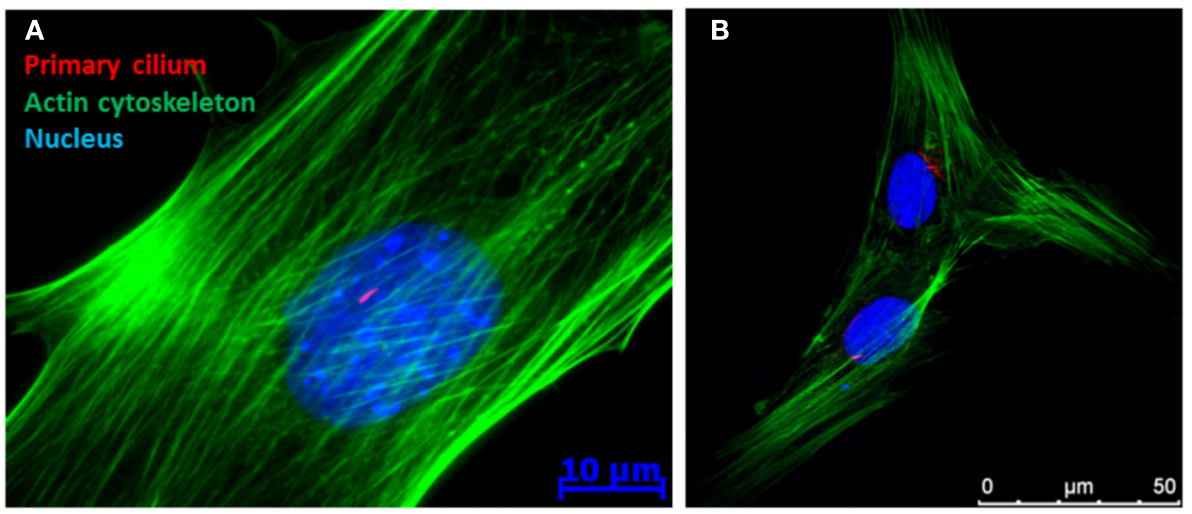

FIGURE 1 | Immunofluorescence image of a (A) MC3T3 (pre-osteoblast) and (B) human mesenchymal stem cell demonstrating the presence of a primary cilium as a rod like structure in the peri-nuclear region of the cell. 
of the primary cilium through RNA interference, the decrease in cAMP in response to flow is lost, demonstrating that this response is cilia-mediated. Adenylyl cyclase (AC) is an enzyme responsible for catalyzing the conversion of cAMP from ATP and various isoforms have been found to localize to the ciliary microdomain in several tissues (Masyuk et al., 2006, 2008; Bishop et al., 2007; Raychowdhury et al., 2009). Of the nine isoforms of AC known to exist, AC2-7 and AC9 were found to be expressed in osteocytes by RT-PCR. Furthermore, utilizing immunocytochemistry, AC6 was the sole isoform found to localize to the osteocyte primary cilium (Figure 2A). As AC6 has previously been shown to be required for flow mediated decreases in cAMP in cholangiocytes, Kwon et al. (2010) investigated AC6's role in the flow mediated decrease in cAMP in osteocytes. Once again using RNA interference, AC6 message was depleted and this corresponded to a significant decrease in AC6 protein expression. Osteocytes with depleted AC6 behaved similarly to osteocytes, which no longer possess a primary cilium, and did not respond to fluid flow stimulation with a decrease in cAMP. AC6 is a calcium ion inhibited isoform of adenylyl cyclase. To investigate whether flow mediated release of intracellular calcium was responsible for the decrease in cAMP, intracellular calcium stores were depleted with thapsigargin treatment. The depletion of stored intracellular calcium had no effect on flow mediated decreases in cAMP in osteocytes. Therefore the role of extracellular $\mathrm{Ca}^{2+}$ entry was investigated by blocking $\mathrm{Ca}^{2+}$ entry through membrane bound channels using $\mathrm{GdCl}$ treatment. Preventing $\mathrm{Ca}^{2+}$ entry into the cell did prevent the flow mediated decrease in cAMP, indicating that calcium entry is an initial trigger of the AC6-cAMP pathway mediating osteocyte primary cilium dependent mechanosensing.

In summary, deflection of the bone cell primary cilium activates, an as of yet unidentified, $\mathrm{GdCl}$ sensitive channel,

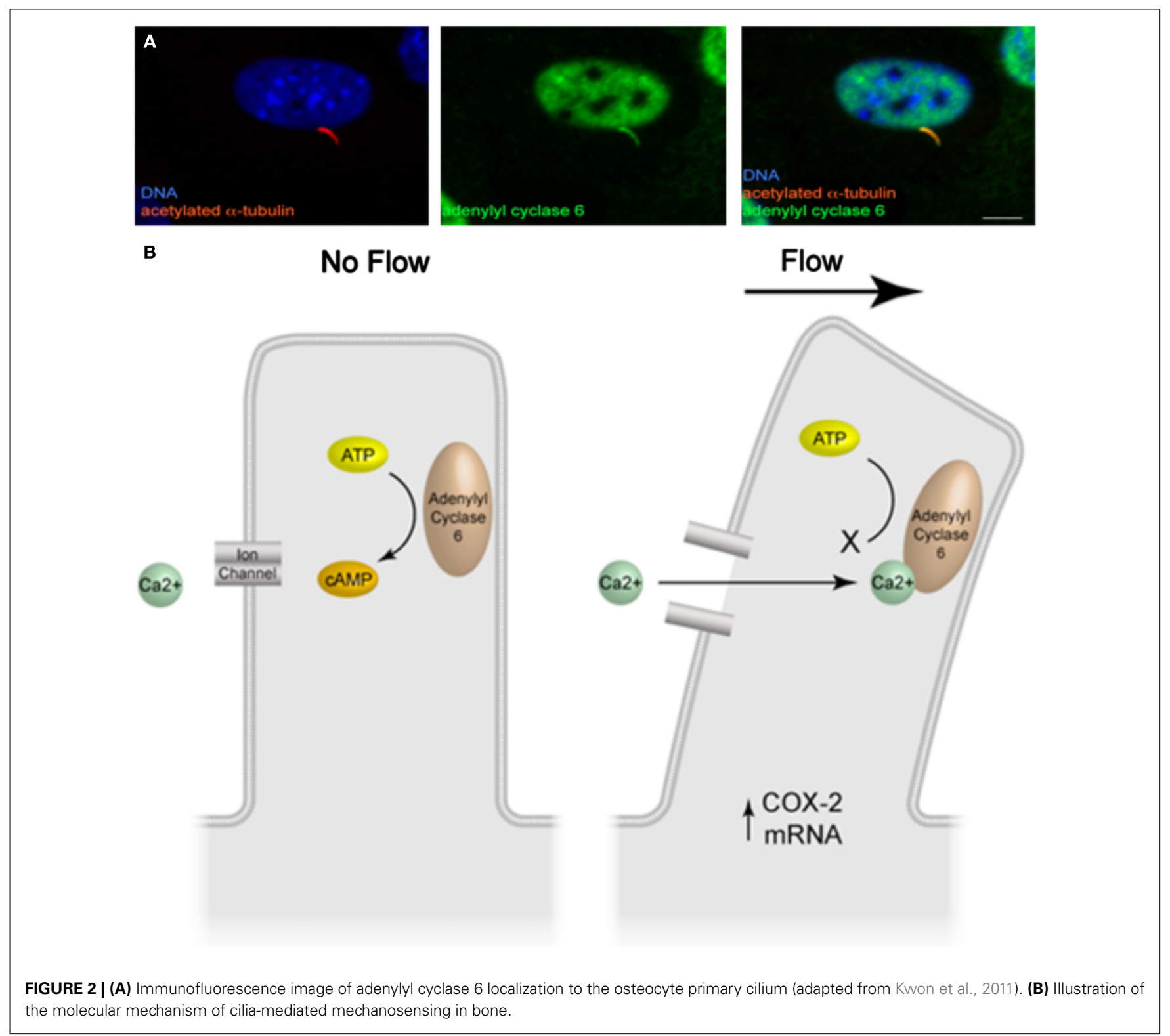


which subsequently inhibits AC6 activity, decreasing cAMP levels resulting in an increase in osteogenic gene expression (Figure 2B).

\section{IN VIVO STUDIES}

Although a role for the primary cilium in bone cell mechanotransduction in vitro has been established above, it is essential to conduct in vivo experiments to determine the physiological relevance of in vitro findings.

As the primary cilium is indispensable for early development, global deletion of the primary cilium is embryonic lethal. Therefore, Temiyasathit et al. (2012) utilized the Cre-lox system to generate a mature bone cell (i.e., osteoblast/osteocyte) specific conditional knockout of the primary cilium. This was achieved by crossing a mouse with a floxed Kif3a gene (Kif3a is an intraflagellar transport protein required for functional ciliogenesis) with a mouse which expresses Cre-recombinase under control of the $2.3 \mathrm{~kb}$ collagen $1 \alpha(\mathrm{I})$ promoter. This promoter drives the expression of Cre-recombinase in osteoblasts and osteocytes leading to the specific deletion of Kif3a in these cells which in turn prevents these cells from forming a functional primary cilium (Figure 3). To determine whether the osteoblast and osteocyte primary cilium are required for normal skeletal development, various skeletal parameters were compared in $\operatorname{Col} 1 \alpha(I)$ 2.3-Cre; Kif $3 a^{f l / f l}$ mice and WT mice throughout development. No difference was found in embryo size, limb patterning, and growth plate architecture at E16.5-18.5 indicating that bone cell primary cilia play a minor role in skeletal development. Furthermore, there was no significant difference in the overall size of the adult skeletons, ulna length, or cortical bone architecture at the ulnar midshaft in knockout animals (KO) compared to control mice at 16 weeks indicating no effect on skeletal morphology in mature animals. Interestingly, a recent study using a cre-recombinase under control of the Osteocalcin-promoter discovered that mice at 6 weeks were osteopenic yet recovered at 24 weeks (Qiu et al., 2012). $\operatorname{Col} 1 \alpha(\mathrm{I})$ 2.3-Cre is expressed throughout osteoblast differentiation, while Osteocalcin-cre expression is limited to mature osteoblasts. Therefore, the Coll $\alpha(I)$ 2.3-Cre; Kif3a fl/fl mouse generated by Temiyasathit et al. (2012) resulted in a more expansive cilium knockout than the Qiu et al. (2012) mouse, yet displayed no

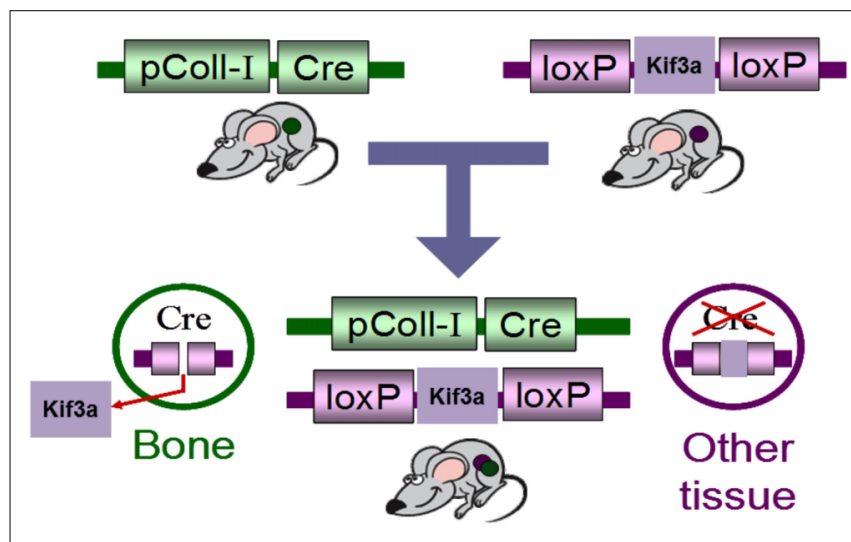

FIGURE 3 | Schematic of the Cre-lox system used to generate of bone specific primary cilium knockout mouse. skeletal abnormalities at 16 weeks. Therefore, these data suggest an age-dependent post-natal cilia-mediated defect in bone formation that is recovered by 16 weeks.

To investigate the role of bone cell primary cilia in loading induced bone formation, 16 week old mice were subjected to compressive loading of the ulna for 120 cycles per day for three consecutive days at a frequency of $2 \mathrm{~Hz}$ with a peak load of $3.4 \mathrm{~N}$ (Temiyasathit et al., 2012). No difference in strain was detected between KO and WT animals as measured by strain gage. Fluorochrome labels were injected at two time points post-loading allowing newly formed bone to be identified, imaged, and quantified. By dynamic histomorphometry the relative mineralizing surface (rMS/BS), mineral apposition rate (rMAR), and bone formation rate (rBFR/BS) were calculated by subtracting the nonloaded from the loaded ulna. Ulna loading resulted in a significant increase in all parameters measured in both $\mathrm{KO}$ and WT animals. However the rMAR and rBFR was significantly less in KO animals demonstrating that deficient primary cilia in osteoblasts and osteocytes results in reduced loading induced bone formation and verifies earlier in vitro data (Figure 4).

As stated above, the enzyme adenylyl cyclase 6 (AC6) was found to localize to the ciliary microdomain of bone cells and was required for cilia-mediated mechanotransduction in osteocytes in vitro (Kwon et al., 2010). To investigate this potential mechanism of cilia-mediated mechanotransduction in bone in vivo, Lee et al. (2012) utilized a mouse with a targeted global deletion of AC6 (Tang et al., 2008). Similar to the Colla(I) 2.3-Cre;Kif3 $a^{f l / f l}$ mice described above, the skeletal morphology of the AC6 KO mice was compared to WT mice. Body weight, tibia and ulna lengths, and trabecular and cortical bone architecture were not significantly different between $A C 6^{-1-}$ and WT mice indicating that AC6, like the primary cilium in mature bone cells, is not required for normal skeletal development. Next, the role of AC6 in loading induced bone formation in vivo, $A C 6^{-1-}$, and WT animals were subjected to compressive ulnar loading as above and bone formation was assayed using dynamic histomorphometry. Both $A C 6^{-1-}$ and WT animals responded to ulnar loading with a significant increase in rMS, rMAR, and rBFR. However, like the bone specific primary cilium KO mouse, the $A C 6^{-1-}$ mouse had a significantly reduced response to ulnar loading compared to WT in all three parameters measured. Although this animal is not a bone specific $A C 6^{-1-}$, these data demonstrate that AC6 is involved in loading induced bone formation in vivo and once again solidifies earlier in vitro data.

\section{PRIMARY CILIA IN OSTEOPROGENITORS}

Although great advances have been made in understanding the role of the primary cilium in mature bone, little is known regarding the role of the primary cilium in osteoprogenitors. It is well established that the primary cilium is pivotal in normal skeletal development (Serra, 2008) but a complete characterization of the skeletal phenotype in mice has proven impossible due to lethality mid-gestation.

Tummala et al. (2010) recently demonstrated the existence of primary cilia on primary human bone marrow derived mesenchymal stem cells (hMSC). Upon staining with anti-acetylated alpha tubulin over $90 \%$ of cells imaged possessed a primary cilium 


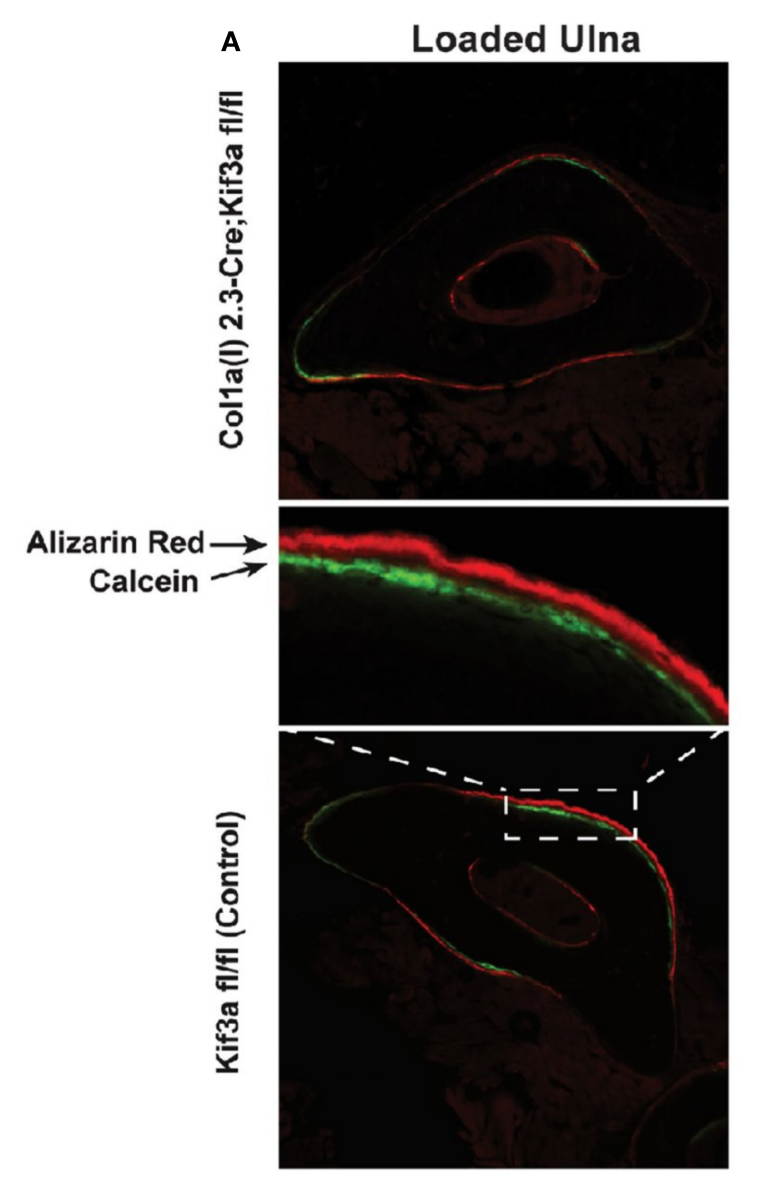

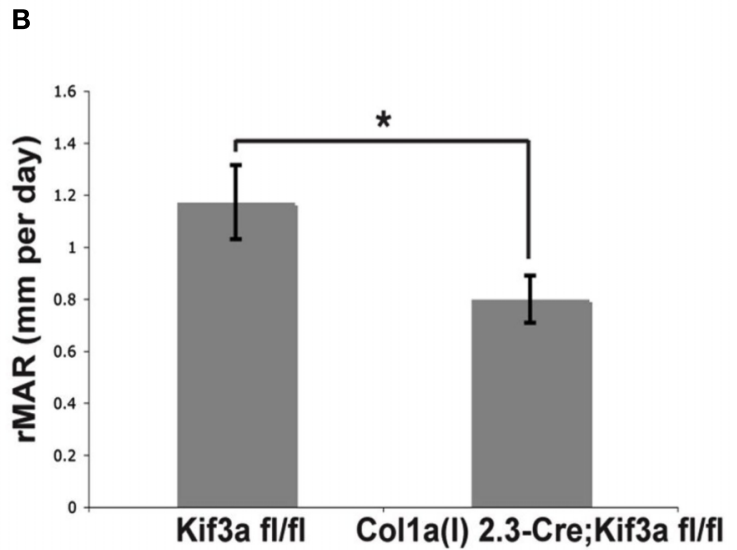

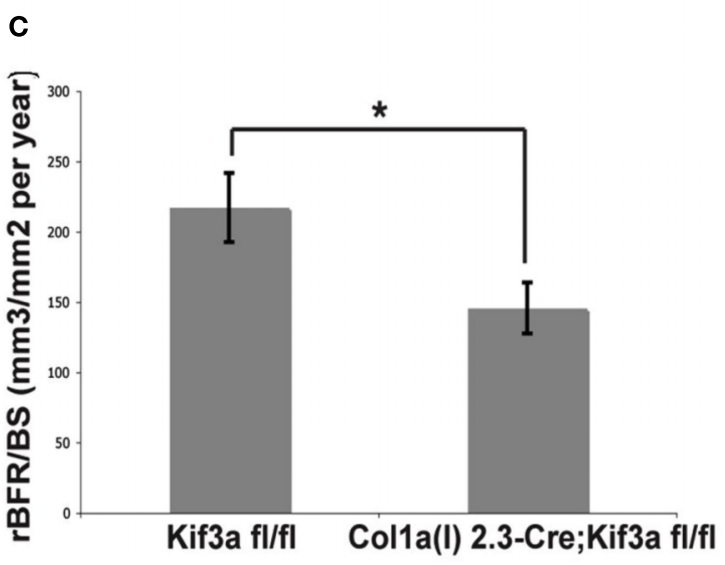

FIGURE 4 | (A) Representative images of loaded ulnae of Col 1 1(I) 2.3-Cre; Kif3 ${ }^{\text {flffl }}$ (top) and control (bottom) mice. (B,C) Relative mineral apposition rate (rMAR, $\mu \mathrm{m}$ per day), and bone formation rate (rBFR/BS, $\mu \mathrm{m}^{3} / \mu \mathrm{m}^{2}$ per year), of mechanically loaded mice. Adapted from Temiyasathit et al. (2012).

extending from the peri-nuclear region of the cell. Utilizing siRNA targeting Polaris as above, the formation of primary cilia was inhibited and the baseline expression of the transcription factors RUNX2 (Bone), SOX9 (Cartilage), and PPAR $\gamma$ (Fat) were quantified. Interestingly, by simply inhibiting the stem cells ability to form a cilium, the expression levels of all three transcription factors was significantly reduced. To investigate whether the cilium is required for biochemically induced differentiation, cilia formation was inhibited and hMSCs were treated with osteogenic, chondrogenic, and adipogenic induction media. Surprisingly, hMSCs with inhibited primary cilia formation and placed in osteogenic and adipogenic media lost their adhesion to the dish but remained viable. This did not occur in chondrogenic media and when the experiment was repeated with fibroblasts indicating that it is lineage and stem cell specific. Furthermore, hMSCs were differentiated down each lineage and cilium formation was inhibited post-induction. This once again resulted in a significantly lower levels of RUNX2, SOX9, and PPAR $\gamma$ (Tummala et al., 2010). These data indicate that the hMSC primary cilium is required for biochemically induced differentiation but how the cilium coordinates this process remains elusive.

Similar to adult bone cells, osteoprogenitors are known to be a mechanosensitive cell type (Li et al., 2004). Therefore, Hoey et al explored the potential role of the primary cilium in human mesenchymal stem cell mechanotransduction (Hoey et al., 2012b). In response to $2 \mathrm{~h}$ of $1 \mathrm{~Pa}$ of oscillatory fluid flow induced shear stress, hMSCs responded with a significant increase in the osteogenic genes COX-2 and BMP-2. Furthermore, similar to findings by Riddle et al. (2007), $2 \mathrm{~h}$ of $2 \mathrm{~Pa}$ of shear stress resulted in a significant increase in the proliferation rate of hMSCs. To investigate the role of the primary cilium in these responses, the formation of the cilium was prevented using siRNA targeting Polaris as above. In terms of osteogenic gene expression, hMSCs which no longer possessed the ability to form a primary cilium did not respond to fluid flow with an increase in COX-2 and BMP-2 demonstrating that the primary cilium is required for hMSC fluid flow mechanotransduction. In addition, hMSCs lacking primary cilia surprisingly responded to flow with an even greater increase in proliferation rate. This perhaps points to a pro-osteogenic role for the primary cilium in hMSC mechanotransduction as increased proliferation is indicative of reduced differentiation. The phenomenon of the primary cilium regulating flow mediated increases in proliferation also parallels proposed models of polycystic kidney disease and suggests that this is not tissue specific (Ong and Wheatley, 2003); therefore this finding has far reaching significance as many 
ciliopathies are characterized by uncontrolled proliferation and cyst formation.

\section{FUTURE DIRECTIONS AND IMPLICATIONS FOR THERAPIES}

Over the past 10 years, the primary cilium has emerged as an important extracellular sensor in bone. Despite extensive steps forward, many more are required to fully delineate the role of the primary cilium in bone and utilize this knowledge in efforts to prevent bone loss through the development of cilium targeted therapeutics.

\section{IN VITRO MODELS}

The greatest challenge ahead in bone primary cilium research is elucidating the molecular mechanisms and identifying the intraciliary and intracellular signaling mechanism involved. Previous work discussed above has revealed that bending of the osteocyte primary cilium activates an unidentified GdCl sensitive channel, which subsequently inhibits AC6 activity, changing cAMP levels and resulting in an increase in osteogenic gene expression. Through the identification of this $\mathrm{GdCl}$ sensitive channel, a novel pharmacologic agent could be utilized to activate this channel thereby mimicking the effect of mechanical loading at a molecular level and shift the remodeling balance. One potential channel is TRPV4 which is a $\mathrm{Ca}^{2+}$-permeable ion channel known to localize to primary cilia (Phan et al., 2009). Depletion of TRPV4 eliminates calcium influx in response to flow (Gradilone et al., 2007; Kottgen et al., 2008), and its deletion also blocks bone mechanosensation in disuse in vivo (Mizoguchi et al., 2008). Therefore, it is plausible that a TRPV4-Ca ${ }^{2+}$-AC6 regulatory relationship could exist in the osteocyte primary cilium microdomain which could mediate the flow induced change in cAMP levels. Another potential $\mathrm{Ca}^{2+}$ permeable ion channel is Polycystin 2 (PC2). PC2 has been shown to localize to the ciliary microdomain and is activated upon cilium deflection (Nauli et al., 2003). However unlike TRPV4, PC2 mutations do not display skeletal defects (Wu et al., 2000).

In order to fully describe the molecular mechanism of ciliamediated mechanosensing, more precise biophysical measurements are needed. The primary cilium is a microdomain that is distinct from the cell cytoplasm, separated by barriers known as alar sheets (Hagiwara et al., 1997; Hoey et al., 2012a). Therefore this allows the cell to exploit the ciliary microdomain as a controlled signaling center capable of concentrating, and enhancing the signaling kinetics. For instance, it is hypothesized above that $\mathrm{Ca}^{2+}$ ion entry into the ciliary microdomain is required for cilia-mediated mechanosensing. However, this ordinarily insignificant level of $\mathrm{Ca}^{2+}$ influx would be undetectable using whole cell techniques such as that utilized in Malone et al. (2007a). As cross talk between $\mathrm{Ca}^{2+}$ and AC activity is known to be strongly enhanced by sequestration in microdomains, such as lipid rafts and caveolae (Smith et al., 2002; Wachten et al., 2010; Willoughby et al., 2010), measurements of secondary messenger signaling within the ciliary microdomain are needed. Possible methods of quantifying $\mathrm{Ca}^{2+}$ and/or cAMP levels within the primary cilium are possible through the use of an indicator based on the calcium chelator BAPTA coupled to rhodamine-based fluorophore and ICUE3, a FRET biosensor, respectively (Hutter, 2004). This allows intraciliary and intracellular second messenger signaling to be distinguished in response to mechanical stimulation. Another approach for distinguishing ciliary populations of signaling molecules would be to physically isolate primary cilia to allow direct biochemical evaluation. Huang et al. (2006) recently developed techniques to physically isolate and characterize cilia and Raychowdhury et al. (2005) developed techniques to refine the isolated cilia. With these techniques, additional biochemical analysis of the primary cilia-associated proteins is straightforward. Finally, to study the necessary localization of activating proteins to the primary cilia microdomain, proteins that are no longer trafficked to primary cilia could be created by mutating amino acids forming newly identified "ciliary targeting sequences" (Berbari et al., 2008; Yoder, 2008; Nachury et al., 2010).

The effect of interfering with primary cilia formation or candidate activation targets in the primary cilium microdomain on downstream signaling involved in bone formation must be evaluated. The primary effector of cAMP is PKA, a major protein kinase involved in various pathways regulating bone formation and has been shown to localize to the base of primary cilia (Tuson et al., 2011). PKA in turn is known to activate the ERK1/2-CREB signaling cascade, which is upregulated by flow in bone cells (You et al., 2001). PKA also inhibits GSK-3 $\beta$-mediated degradation of the transcription factor $\beta$-Catenin, the nuclear translocation of which has also been shown to occur with flow in osteogenesis (Arnsdorf et al., 2009). Interestingly, primary cilia have been recently implicated in both the ERK and $\beta$-Catenin pathways (Christensen et al., 2012). Therefore, disruption of the primary cilium may deregulate numerous downstream pathways involved in bone formation (Figure 5).

\section{IN VIVO MODELS}

While in vitro studies are critical for determining the molecular mechanism of primary cilia-mediated mechanosensing, in vivo studies are necessary for clearly implicating these mechanosensitive molecules in bone formation and provide a tool whereby we could demonstrate an ability to manipulate them to prevent bone loss. TRPV4 ${ }^{-1-}$ mice have been generated and are normal in size and appearance, but are less sensitive to tail pressures (Suzuki et al., 2003). Interestingly, TRPV4 $4^{-1-}$ mice exhibit no skeletal defects, yet have a diminished bone loss in response to unloading (Mizoguchi et al., 2008). The response of these mice to external loading is currently unknown, but TRPV4 ${ }^{-1-}$ mice would be expected to exhibit a blunted sensitivity to loading, similar to $A C 6^{-1-}$ and $\operatorname{Col} 1 \alpha(I)$ 2.3-Cre;Kif $3 a^{f l f l}$ mice.

Previous work detailed above has demonstrated an important sensory role for primary cilia in osteocytes, osteoblasts, and osteoprogenitor cells. However, the specific role of primary cilia as a mechanosensor facilitating loading induced bone adaptation for each of these specific cellular subpopulations remains unclear. Results from in vivo loading or unloading studies utilizing transgenic animals with impaired primary cilia formation for each subpopulation of cells would be informative. A CreLox recombination system is one approach. As mentioned previously, Coll $\alpha$ (I) 2.3-Cre; Kif3 $a^{f l / f l}$ animals exhibit reduced loading induced bone formation as compared to WT animals. Although this demonstrates that primary cilia are important in osteoblasts and osteocytes, this does not distinguish the role of primary 


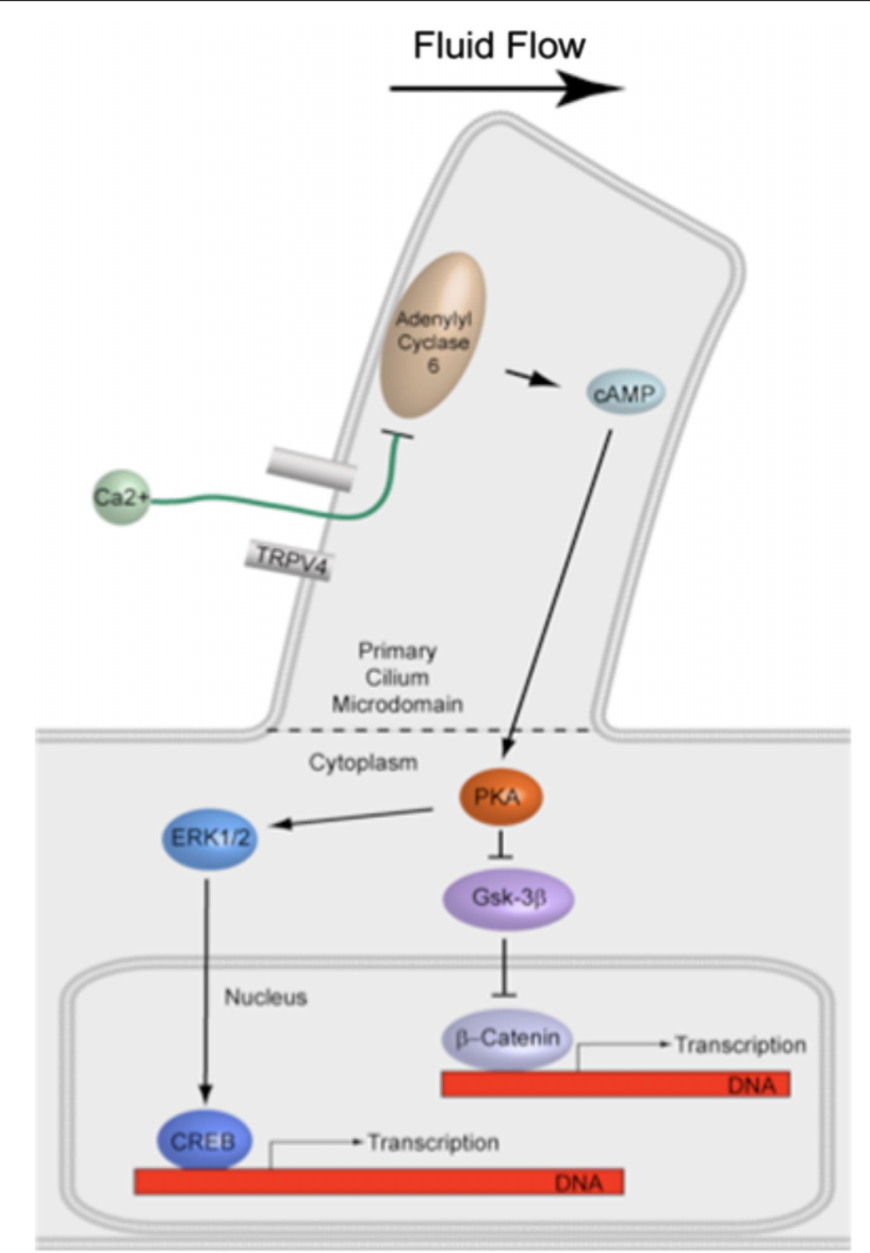

FIGURE 5 | Illustration of proposed signaling downstream of cilia-mediated mechanosensing in bone. PKA is known to activate the ERK1/2-CREB signaling cascade and also inhibit

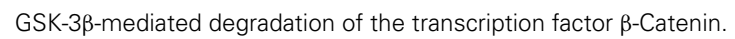
Both pathways have been shown to be involved in fluid flow mechanotransduction in bone. cilia in osteocytes from osteoblasts. An 8-kb DMP1-Cre was recently shown to produce osteocyte-specific recombination (Bivi et al., 2012). Using this system, IFT88 or Kif3a (Lin et al., 2003; Temiyasathit et al., 2012), which are both important for primary cilia formation, could be specifically targeted for deletion in osteocytes. Should loading in these animals result in similar reductions in bone formation, this would indicate that primary cilia in osteocytes, rather than osteoblasts, are primarily responsible for the reduction observed in the Coll $\alpha(I)$ 2.3-Cre;Kif3 $a^{f l / f l}$ animals. Animal models with impaired primary cilia formation in osteoprogenitor cell populations are less straightforward. As primary cilia are required for development, deletion of genes required for primary cilia formation in progenitor cells would result in embryonic lethality. One approach is to create chimeric animals by performing a bone marrow transplant using cells from an $I F T 88^{f l / f l}$ or Kif $3 a^{f l / f l}$ donor that has been treated with Crerecombinase ex vivo. Stem cells derived from the bone marrow in these animals would not have functional primary cilia. Another approach would be to use an inducible Cre promoter. A $2.4-\mathrm{kb}$ Prx1-CreER-GFP produces tamoxifen-induced recombination in periosteal cells (Kawanami et al., 2009), and an Mxl promoter drives inducible recombination in bone marrow stromal cells (Park et al., 2012). However, bone marrow stromal cells expressing Mx1 may not include all cells capable of differentiation down the osteogenic lineage. If animals with primary cilia formation inhibited in osteoblasts, osteocytes, or osteoprogenitors were to exhibit a similar decrease in response to loading as global knockouts of AC6 and TRPV4, then this would suggest these targets are involved in the same mechanostransduction pathway. One way to test whether the ciliary pool of AC6 or TRPV4 is responsible for loss of mechanosensitivity in the $A C 6^{-1-}, T R P V 4^{-1-}$ animals would be to generate animals with both the conditional deletion of IFT88 and global deletion of AC6 or TRPV4. If the ciliary pools are important, then adding the conditional deletion of IFT88 should have no additional bone mechanosensing deficit compared to the AC6 and TRPV4 deletions alone. In this way, in vivo studies can be very informative of the role of primary cilia in specific cell populations in mechanically induced bone adaptation, as well as the molecular mechanisms that enable primary cilia to act as mechanosensors. 
Another interesting question which remains unanswered is the incidence, location, and orientation of the primary cilium within the osteocyte lacunae in vivo. The pericellular space within the osteocyte lacunae ranges from 0.1 to $2.7 \mu \mathrm{m}$ (McNamara et al., 2009), yet the osteocyte primary cilium extends $4-9 \mu \mathrm{m}$ in length based on in vitro observations (Malone et al., 2007a). Given this discrepancy, it is plausible that the bending of the cilium under fluid flow, similar to that witnessed in the kidney, is not the activating mechanism in cilia-mediated mechanosensing. Alternatively, the primary cilium in bone may act in a similar manner to the cilium in cartilage, where the chondrocyte primary cilium is directly connected to the pericellular matrix through integrin proteins (McGlashan et al., 2006). Therefore stretching rather than bending of the primary cilium under flow may be the activating mechanism. Fixation techniques similar to that used by McNamara et al. (2009) which preserve the pericellular matrix surrounding the osteocyte in vivo in combination with TEM imaging will reveal incidence, location, and orientation of the primary cilium and provide insight into the activating mechanism of cilia-mediated mechanosensing in bone in vivo.

\section{POTENTIAL CILIUM TARGETED THERAPEUTICS}

Elucidating how downstream intracellular signaling cascades are affected by mechanically induced cAMP signaling would provide a wealth of potential therapeutic targets. Therapies aimed at changing the levels or activities of molecules involved in these cascades could be created specifically to mimic the effect of mechanical stimulation. Additionally, therapeutics modulating cAMP signaling could be another avenue for encouraging bone formation. Agonists for TRPV4 include 4 - $\alpha$-phorbol 12,13-didecanoate ( $4 \alpha$ PDD) and RN-1747 (Vincent et al., 2009). Treatment of osteoblasts in vitro with $4 \alpha \mathrm{PDD}$ resulted in increased levels of COX-2 expression relative to vehicle control, indicating that activation of

\section{REFERENCES}

Arnsdorf, E. J., Tummala, P., and Jacobs, C. R. (2009). Non-canonical Wnt signaling and $\mathrm{N}$-cadherin related beta-catenin signaling play a role in mechanically induced osteogenic cell fate. PLoS ONE 4, e5388. doi:10.1371/journal.pone.0005388

Benton, R., Sachse, S., Michnick, S. W., and Vosshall, L. B. (2006). Atypical membrane topology and heteromeric function of Drosophila odorant receptors in vivo. PLoS Biol. 4, e20. doi:10.1371/journal.pbio.0040020

Berbari, N. F., Johnson, A. D., Lewis, J. S., Askwith, C. C., and Mykytyn, K. (2008). Identification of ciliary localization sequences within the third intracellular loop of $G$ protein-coupled receptors. Mol. Biol. Cell 19, 1540-1547.

Besschetnova, T. Y., Kolpakova-Hart, E., Guan, Y., Zhou, J., Olsen, B. R., and Shah, J. V. (2010). Identification of signaling pathways regulating

TRPV4 through pharmacological means may mimic the effects of mechanical stimulation (unpublished data). Administration of $4 \alpha \mathrm{PDD}$ in vivo, then, could potentially lead to similar effects on bone formation as mechanical loading. Detection of loading induced intraciliary second messenger signaling, identification of the responsible mechanism(s), and determining how intraciliary signaling is important for regulating downstream intracellular signaling are all exciting research directions. Together, the results from these studies would identify the molecular mechanism responsible for primary-cilia-dependent mechanosensing and could provide new insights into therapeutic treatments to mimic the anabolic effect of physical loading.

\section{CONCLUSION}

The past decade of research has resulted in the primary cilium emerging as a novel extracellular senor in bone, being required to transduce changes in the extracellular mechanical environment into biochemical responses regulating bone adaptation. The primary cilium has also displayed pivotal roles in regulating the osteogenic fate of progenitor cells. As research intensifies, the full potential of this primary cilium in regulating skeletal homeostasis will become evident. Furthermore, as progress continues in delineating the molecular mechanisms of primary cilia-mediated sensing in bone, the development of primary cilia-targeted therapeutics will be developed with the hope of mimicking the anabolic effect of physical loading, which would greatly aid in the treatment of bone loss diseases such as osteoporosis.

\section{ACKNOWLEDGMENTS}

Funding provided by a New York State Stem Cell grant (N089-210) and NIH grants (AR45989, AR54156, and AR62177). The authors would also like to acknowledge R.Y. Kwon for contributing images (Figure 2).

B., Qiu, J., and Duncan, R. L. (2000). $\mathrm{Ca}(2+)$ regulates fluid shearinduced cytoskeletal reorganization and gene expression in osteoblasts. Am. J. Physiol. Cell Physiol. 278, C989-C997.

Christensen, S. T., Clement, C. A., Satir, P., and Pedersen, L. B. (2012). Primary cilia and coordination of receptor tyrosine kinase (RTK) signalling. J. Pathol. 226, 172-184.

Donahue, T. L., Haut, T. R., Yellowley, C. E., Donahue, H. J., and Jacobs, C. R. (2003). Mechanosensitivity of bone cells to oscillating fluid flow induced shear stress may be modulated by chemotransport. J. Biomech. 36, 1363-1371.

Donnelly, E., Ascenzi, M. G., and Farnum, C. (2010). Primary cilia are highly oriented with respect to collagen direction and long axis of extensor tendon. J. Orthop. Res. 28, 77-82.
Downs, M. E., Nguyen, A. M., Herzog, F. A., Hoey, D. A., and Jacobs, C. R. (2012). An experimental and computational analysis of primary cilia deflection under fluid flow. Comput. Methods Biomech. Biomed. Engin. doi:10.1080/10255842.2011. 653784

Ecker, A. (1844). Flimmerbewegung im Gehörorgan von Petromyzon marinus. Arch. Anat. Physiol. Wiss. Med. (Müller's Archiv) 520-521.

Elias, R. V., Sezate, S. S., Cao, W., and McGinnis, J. F. (2004). Temporal kinetics of the light/dark translocation and compartmentation of arrestin and alpha-transducin in mouse photoreceptor cells. Mol. Vis. 10, 672-681.

Gardner, K., Arnoczky, S. P., and Lavagnino, M. (2011). Effect of in vitro stress-deprivation and cyclic loading on the length of tendon cell cilia in situ. J. Orthop. Res. 29, 582-587. 
Gradilone, S. A., Masyuk, A. I., Splinter, P. L., Banales, J. M., Huang, B. Q., Tietz, P. S., Masyuk, T. V., and Larusso, N. F. (2007). Cholangiocyte cilia express TRPV4 and detect changes in luminal tonicity inducing bicarbonate secretion. Proc. Natl. Acad. Sci. U.S.A. 104, 19138-19143.

Hagiwara, H., Aoki, T., and Fujimoto, T. (1997). Ultrastructural observation on "transitional tubules" in human oviductal ciliogenic cells. J. Anat. 191, 285-290.

Hierck, B. P., Van der Heiden, K., Alkemade, F. E., Van de Pas, S., Van Thienen, J. V., Groenendijk, B. C., Bax, W. H., Van der Laarse, A., Deruiter, M. C., Horrevoets, A. J., and Poelmann, R. E. (2008). Primary cilia sensitize endothelial cells for fluid shear stress. Dev. Dyn. 237, 725-735.

Hildebrandt, F., Benzing, T., and Katsanis, N. (2011). Ciliopathies. N. Engl. J. Med. 364, 1533-1543.

Hoey, D. A., Downs, M. E., and Jacobs, C. R. (2012a). The mechanics of the primary cilium: an intricate structure with complex function. J. Biomech. 45, 17-26.

Hoey, D. A., Tormey, S. J., O’Brien, J. F., and Jacobs, C. R. (2012b). A Mechanosensory Role for the Primary Cilium in Human Mesenchymal Stem Cells. San Francisco: Orthopaedic Research Society.

Hoey, D. A., Kelly, D. J., and Jacobs, C. R. (2011). A role for the primary cilium in paracrine signaling between mechanically stimulated osteocytes and mesenchymal stem cells. Biochem. Biophys. Res. Commun. 412, 182-187.

Huang, B. Q., Masyuk, T. V., Muff, M. A., Tietz, P. S., Masyuk, A. I., and Larusso, N. F. (2006). Isolation and characterization of cholangiocyte primary cilia. Am. J. Physiol. Gastrointest. Liver Physiol. 291, G500-G509.

Hutter, H. (2004). Five-colour in vivo imaging of neurons in Caenorhabditis elegans. J. Microsc. 215( $\mathrm{Pt} 2)$, 213-218.

Jacobs, C. R., Temiyasathit, S., and Castillo, A. B. (2010). Osteocyte mechanobiology and pericellular mechanics. Annu. Rev. Biomed. Eng. 12, 369-400.

Jacobs, C. R., Yellowley, C. E., Davis, B. R., Zhou, Z., Cimbala, J. M., and Donahue, H. J. (1998). Differential effect of steady versus oscillating flow on bone cells. J. Biomech. 31, 969-976.

Kaushik, A. P., Martin, J. A., Zhang, Q. H., Sheffield, V. C., and Morcuende,
J. A. (2009). Cartilage abnormalities associated with defects of chondrocytic primary cilia in Bardet-Biedl syndrome mutant mice. J. Orthop. Res. 27, 1093-1099.

Kawanami, A., Matsushita, T., Chan, Y. Y., and Murakami, S. (2009). Mice expressing GFP and CreER in osteochondro progenitor cells in the periosteum. Biochem. Biophys. Res. Commun. 386, 477-482.

Kim, C. H., You, L., Yellowley, C. E., and Jacobs, C. R. (2006). Oscillatory fluid flow-induced shear stress decreases osteoclastogenesis through RANKL and OPG signaling. Bone 39, 1043-1047.

Klein-Nulend, J., Semeins, C. M., Ajubi, N. E., Nijweide, P. J., and Burger, E. H. (1995). Pulsating fluid flow increases nitric oxide (NO) synthesis by osteocytes but not periosteal fibroblasts - correlation with prostaglandin upregulation. Biochem. Biophys. Res. Commun. 217, 640-648.

Knight, M. M., McGlashan, S. R., Garcia, M., Jensen, C. G., and Poole, C. A. (2009). Articular chondrocytes express connexin 43 hemichannels and P2 receptors - a putative mechanoreceptor complex involving the primary cilium? J. Anat. 214, 275-283.

Kottgen, M., Buchholz, B., GarciaGonzalez, M. A., Kotsis, F., Fu, X., Doerken, M., Boehlke, C., Steffl, D., Tauber, R., Wegierski, T., Nitschke, R., Suzuki, M., Kramer-Zucker, A., Germino, G. G., Watnick, T., Prenen, J., Nilius, B., Kuehn, E. W., and Walz, G. (2008). TRPP2 and TRPV4 form a polymodal sensory channel complex. J. Cell Biol. 182, 437-447.

Krieger, J., Schleicher, S., Strotmann, J., Wanner, I., Boekhoff, I., Raming, K., De Geus, P., and Breer, H. (1994). Probing olfactory receptors with sequence-specific antibodies. Eur. J. Biochem. 219, 829-835.

Kwon, R. Y., Hoey, D. A., and Jacobs, C. R. (2011). "Mechanobiology of primary cilia," in Cellular and Biomolecular Mechanics and Mechanobiology, ed. A. Gefen, Vol. 4 (Heidelberg: SpringerLink), 99-124.

Kwon, R. Y., Temiyasathit, S., Tummala, P., Quah, C. C., and Jacobs, C. R. (2010). Primary cilium-dependent mechanosensing is mediated by adenylyl cyclase 6 and cyclic AMP in bone cells. FASEB J. 24, 2859-2868.

Lee, K. L., Hoey, D. A., and Jacobs, C. R. (2010). Primary cilia-mediated mechanotransduction in bone. Clin. Rev. Bone Miner. Metab. 8, 201-212.
Lee, K. L., Hoey, D. A., Tang, T., Hammond, K., and Jacobs, C. R. (2012). Adenylyl Cyclase 6 Mediates Bone Adaptation In vivo. San Francisco: Orthopaedic Research Society.

Li, T., Snyder, W. K., Olsson, J. E., and Dryja, T. P. (1996). Transgenic mice carrying the dominant rhodopsin mutation P347S: evidence for defective vectorial transport of rhodopsin to the outer segments. Proc. Natl. Acad. Sci. U.S.A. 93, 14176-14181.

Li, Y. J., Batra, N. N., You, L., Meier, S. C., Coe, I. A., Yellowley, C. E., and Jacobs, C. R. (2004). Oscillatory fluid flow affects human marrow stromal cell proliferation and differentiation. J. Orthop. Res. 22, 1283-1289.

Lin, F., Hiesberger, T., Cordes, K., Sinclair, A. M., Goldstein, L. S., Somlo, S., and Igarashi, P. (2003). Kidneyspecific inactivation of the KIF3A subunit of kinesin-II inhibits renal ciliogenesis and produces polycystic kidney disease. Proc. Natl. Acad. Sci. U.S.A. 100, 5286-5291.

Litzenberger, J. B., Kim, J. B., Tummala, P., and Jacobs, C. R. (2010). Betal integrins mediate mechanosensitive signaling pathways in osteocytes. Calcif. Tissue Int. 86, 325-332.

Malone, A. M., Anderson, C. T. Tummala, P., Kwon, R. Y., Johnston, T. R., Stearns, T., and Jacobs, C. R. (2007a). Primary cilia mediate mechanosensing in bone cells by a calcium-independent mechanism. Proc. Natl. Acad. Sci. U.S.A. 104, 13325-13330.

Malone, A. M., Batra, N. N., Shivaram, G., Kwon, R. Y., You, L., Kim C. H., Rodriguez, J., Jair, K., and Jacobs, C. R. (2007b). The role of actin cytoskeleton in oscillatory fluid flow-induced signaling in MC3T3E1 osteoblasts. Am. J. Physiol. Cell Physiol. 292, C1830-C1836.

Masyuk, A. I., Gradilone, S. A., Banales, J. M., Huang, B. Q., Masyuk, T. V., Lee, S. O., Splinter, P. L., Stroope, A. J., and Larusso, N. F. (2008). Cholangiocyte primary cilia are chemosensory organelles that detect biliary nucleotides via P2Y12 purinergic receptors. Am. J. Physiol. Gastrointest. Liver Physiol. 295, G725-G734.

Masyuk, A. I., Masyuk, T. V., Splinter, P. L., Huang, B. Q., Stroope, A. J., and LaRusso, N. F. (2006). Cholangiocyte cilia detect changes in luminal fluid flow and transmit them into intracellular $\mathrm{Ca} 2+$ and cAMP signaling. Gastroenterology 131, 911-920.

McGlashan, S. R., Haycraft, C. J., Jensen, C. G., Yoder, B. K., and Poole, C. A. (2007). Articular cartilage and growth plate defects are associated with chondrocyte cytoskeletal abnormalities in Tg737orpk mice lacking the primary cilia protein polaris. Matrix Biol. 26, 234-246.

McGlashan, S. R., Jensen, C. G., and Poole, C. A. (2006). Localization of extracellular matrix receptors on the chondrocyte primary cilium. J. Histochem. Cytochem. 54, 1005-1014.

McGlashan, S. R., Knight, M. M., Chowdhury, T. T., Joshi, P., Jensen, C. G., Kennedy, S., and Poole, C. A. (2010). Mechanical loading modulates chondrocyte primary cilia incidence and length. Cell Biol. Int. 34, 441-446.

McNamara, L. M., Majeska, R. J., Weinbaum, S., Friedrich, V., and Schaffler, M. B. (2009). Attachment of osteocyte cell processes to the bone matrix. Anat. Rec. (Hoboken) 292, 355-363.

Mizoguchi, F., Mizuno, A., Hayata, T. Nakashima, K., Heller, S., Ushida, T., Sokabe, M., Miyasaka, N., Suzuki, M., Ezura, Y., and Noda, M. (2008). Transient receptor potential vanilloid 4 deficiency suppresses unloading-induced bone loss. J. Cell. Physiol. 216, 47-53.

Nachury, M. V., Seeley, E. S., and Jin, H. (2010). Trafficking to the ciliary membrane: how to get across the periciliary diffusion barrier? Annu. Rev. Cell Dev. Biol. 26, 59-87.

Nauli, S. M., Alenghat, F. J., Luo, Y., Williams, E., Vassilev, P., Li, X., Elia, A. E., Lu, W., Brown, E. M., Quinn, S. J., Ingber, D. E., and Zhou, J. (2003). Polycystins 1 and 2 mediate mechanosensation in the primary cilium of kidney cells. Nat. Genet.33, 129-137.

Nauli, S. M., and Zhou, J. (2004). Polycystins and mechanosensation in renal and nodal cilia. Bioessays 26, 844-856.

Ong, A. C., and Wheatley, D. N. (2003). Polycystic kidney disease - the ciliary connection. Lancet 361, 774-776.

Park, D., Spencer, J. A., Koh, B. I., Kobayashi, T., Fujisaki, J., Clemens, T. L., Lin, C. P., Kronenberg, H M., and Scadden, D. T. (2012). Endogenous bone marrow MSCs are dynamic, fate-restricted participants in bone maintenance and regeneration. Cell Stem Cell 10, 259-272.

Phan, M. N., Leddy, H. A., Votta, B. J., Kumar, S., Levy, D. S., Lipshutz, D. B., Lee, S. H., Liedtke, W., and Guilak, F. (2009). Functional characterization of TRPV4 as an osmotically sensitive ion channel in porcine articular chondrocytes. Arthritis Rheum. 60, 3028-3037.

Praetorius, H. A., and Spring, K. R. (2001). Bending the MDCK cell 
primary cilium increases intracellular calcium. J. Membr. Biol. 184, 71-79.

Praetorius, H. A., and Spring, K. R. (2005). A physiological view of the primary cilium. Annu. Rev. Physiol. 67, 515-529.

Price, C., Zhou, X., Li, W., and Wang, L. (2011). Real-time measurement of solute transport within the lacunarcanalicular system of mechanically loaded bone: direct evidence for load-induced fluid flow. J. Bone Miner. Res. 26, 277-285.

Qiu, N., Xiao, Z., Cao, L., Buechel, M. M., David, V., Roan, E., and Quarles, L. D. (2012). Disruption of Kif3a in osteoblasts results in defective bone formation and osteopenia. J. Cell Sci. 125, 1945-1957.

Raychowdhury, M. K., McLaughlin, M., Ramos, A. J., Montalbetti, N., Bouley, R., Ausiello, D. A., and Cantiello, H. F. (2005). Characterization of single channel currents from primary cilia of renal epithelial cells. J. Biol. Chem. 280, 34718-34722.

Raychowdhury, M. K., Ramos, A. J., Zhang, P., McLaughin, M., Dai, X. Q., Chen, X. Z., Montalbetti, N., Del Rocio Cantero, M., Ausiello, D. A., and Cantiello, H. F. (2009). Vasopressin receptormediated functional signaling pathway in primary cilia of renal epithelial cells. Am. J. Physiol. Renal Physiol. 296, F87-F97.

Riddle, R. C., Taylor, A. F., Rogers, J. R., and Donahue, H. J. (2007). ATP release mediates fluid flow-induced proliferation of human bone marrow stromal cells. J. Bone Miner. Res. 22, 589-600.

Rubin, C. T., and Lanyon, L. E. (1984). Regulation of bone formation by applied dynamic loads. J. Bone Joint Surg. Am. 66, 397-402.

Rubin, J., Rubin, C., and Jacobs, C. R. (2006). Molecular pathways mediating mechanical signaling in bone. Gene 367, 1-16.

Saunders, M. M., You, J., Zhou, Z., Li, Z., Yellowley, C. E., Kunze, E. L., Jacobs, C. R., and Donahue, H. J. (2003). Fluid flowinduced prostaglandin E2 response of osteoblastic ROS 17/2.8 cells is gap junction-mediated and independent of cytosolic calcium. Bone 32, 350-356.

Schwartz, E. A., Leonard, M. L., Bizios, R., and Bowser, S. S. (1997). Analysis and modeling of the primary cilium bending response to fluid shear. Am. J. Physiol. 272(1 Pt 2), F132-F138.
Serra, R. (2008). Role of intraflagellar transport and primary cilia in skeletal development. Anat. Rec. (Hoboken) 291, 1049-1061.

Singla, V., and Reiter, J. F. (2006). The primary cilium as the cell's antenna: signaling at a sensory organelle. Science 313, 629-633.

Smith, K. E., Gu, C., Fagan, K. A., Hu, B., and Cooper, D. M. (2002). Residence of adenylyl cyclase type 8 in caveolae is necessary but not sufficient for regulation by capacitative $\mathrm{Ca}(2+)$ entry. J. Biol. Chem. 277, 6025-6031.

Suzuki, M., Mizuno, A., Kodaira, K., and Imai, M. (2003). Impaired pressure sensation in mice lacking TRPV4. J. Biol. Chem. 278, 22664-22668.

Tang, T., Gao, M. H., Lai, N. C., Firth, A. L., Takahashi, T., Guo, T., Yuan, J. X., Roth, D. M., and Hammond, H. K. (2008). Adenylyl cyclase type 6 deletion decreases left ventricular function via impaired calcium handling. Circulation 117, 61-69.

Tatsumi, S., Ishii, K., Amizuka, N., Li, M., Kobayashi, T., Kohno, K., Ito, M., Takeshita, S., and Ikeda, K. (2007). Targeted ablation of osteocytes induces osteoporosis with defective mechanotransduction. Cell Metab. 5, 464-475.

Taylor, A. F., Saunders, M. M., Shingle, D. L., Cimbala, J. M., Zhou, Z., and Donahue, H. J. (2007). Mechanically stimulated osteocytes regulate osteoblastic activity via gap junctions. Am. J. Physiol. Cell Physiol. 292, C545-C552.

Temiyasathit, S., Tang, W. J., Leucht, P., Anderson, C. T., Monica, S. D., Castillo, A. B., Helms, J. A., Stearns, T., and Jacobs, C. R. (2012). Mechanosensing by the primary cilium: deletion of Kif3A reduces bone formation due to loading. PLoS ONE 7, e33368. doi:10.1371/journal.pone. 0033368

Tonna, E. A., and Lampen, N. M. (1972). Electron microscopy of aging skeletal cells. I. Centrioles and solitary cilia. J. Gerontol. 27, 316-324.

Tummala, P., Arnsdorf, E. J., and Jacobs, C. R. (2010). The role of primary cilia in mesenchymal stem cell differentiation: a pivotal switch in guiding lineage commitment. Cell. Mol. Bioeng. 3, 207-212.

Tuson, M., He, M., and Anderson, K. V. (2011). Protein kinase A acts at the basal body of the primary cilium to prevent Gli2 activation and ventralization of the mouse neural tube. Development 138, 4921-4930.

Veland, I. R., Awan, A., Pedersen, L. B., Yoder, B. K., and Christensen, S. T. (2009). Primary cilia and signaling pathways in mammalian development, health and disease. Nephron Physiol. 111, p39-p53.

Vincent, F., Acevedo, A., Nguyen, M. T., Dourado, M., DeFalco, J., Gustafson, A., Spiro, P., Emerling, D. E., Kelly, M. G., and Duncton, M. A. (2009). Identification and characterization of novel TRPV4 modulators. Biochem. Biophys. Res. Commun. 389, 490-494.

Wachten, S., Masada, N., Ayling, L. J., Ciruela, A., Nikolaev, V. O., Lohse, M. J., and Cooper, D. M. (2010). Distinct pools of cAMP centre on different isoforms of adenylyl cyclase in pituitary-derived GH3B6 cells. J. Cell. Sci. 123(Pt 1), 95-106.

Wang, Y. L., McNamara, L. M., Schaffler, M. B., and Weinbaum, S. (2007). A model for the role of integrins in flow induced mechanotransduction in osteocytes. Proc. Natl. Acad. Sci. U.S.A. 104, 15941-15946.

Wann, A. K., Zuo, N., Haycraft, C. J., Jensen, C. G., Poole, C. A., McGlashan, S. R., and Knight, M. M. (2012). Primary cilia mediate mechanotransduction through control of ATP-induced $\mathrm{Ca} 2+$ signaling in compressed chondrocytes. FASEB J. 26, 1663-1671.

Whitfield, J. F. (2003). Primary cilium - is it an osteocyte's strainsensing flowmeter? J. Cell. Biochem. 89, 233-237.

Willoughby, D., Wachten, S., Masada, N., and Cooper, D. M. (2010). Direct demonstration of discrete $\mathrm{Ca} 2+$ microdomains associated with different isoforms of adenylyl cyclase. J. Cell Sci. 123(Pt 1), 107-117.

Wolff, J. (1892). Das Gesetz der Transformation der Knochen. Berlin: Hirschwald.

Wu, G. Q., Markowitz, G. S., Li, L., D’Agati, V. D., Factor, S. M., Geng, L., Tibara, S., Tuchman, J., Cai, Y. Q., Park, J. H., van Adelsberg, J., Hou, H., Kucherlapati, R., Edelmann, W., and Somlo, S. (2000). Cardiac defects and renal failure in mice with targeted mutations in $\mathrm{Pkd} 2$. Nat. Genet. 24, 75-78.

Xiao, Z., Zhang, S., Mahlios, J., Zhou, G., Magenheimer, B. S., Guo, D., Dallas, S. L., Maser, R.,
Calvet, J. P., Bonewald, L., and Quarles, L. D. (2006). Cilia-like structures and polycystin-1 in osteoblasts/osteocytes and associated abnormalities in skeletogenesis and Runx2 expression. J. Biol. Chem. 281, 30884-30895.

Yoder, B. K. (2008). Ciliary Function in Mamalian Development. Burlington, MA: Academic Press.

You, J., Reilly, G. C., Zhen, X., Yellowley, C. E., Chen, Q., Donahue, H. J., and Jacobs, C. R. (2001). Osteopontin gene regulation by oscillatory fluid flow via intracellular calcium mobilization and activation of mitogenactivated protein kinase in MC3T3E1 osteoblasts. J. Biol. Chem. 276, 13365-13371.

You, J., Yellowley, C. E., Donahue, H. J., Zhang, Y., Chen, Q., and Jacobs, C. R. (2000). Substrate deformation levels associated with routine physical activity are less stimulatory to bone cells relative to loadinginduced oscillatory fluid flow. J. Biomech. Eng. 122, 387-393.

You, L., Temiyasathit, S., Lee, P., Kim, C. H., Tummala, P., Yao, W., Kingery, W., Malone, A. M., Kwon, R. Y., and Jacobs, C. R. (2008). Osteocytes as mechanosensors in the inhibition of bone resorption due to mechanical loading. Bone 42, 172-179.

Zimmerman, K. W. (1898). Beitrage zur Kenntniss einiger Drusen und Epithelien. Arch. Mikrosk. Anat. 52, 552-706.

Conflict of Interest Statement: The authors declare that the research was conducted in the absence of any commercial or financial relationships that could be construed as a potential conflict of interest.

Received: 10 April 2012; paper pending published: 01 May 2012; accepted: 21 May 2012; published online: 13 June 2012.

Citation: Hoey DA, Chen JC and Jacobs CR (2012) The primary cilium as a novel extracellular sensor in bone. Front. Endocrin. 3:75. doi: 10.3389/fendo.2012.00075

This article was submitted to Frontiers in Bone Research, a specialty of Frontiers in Endocrinology.

Copyright (c) 2012 Hoey, Chen and Jacobs. This is an open-access article distributed under the terms of the Creative Commons Attribution Non Commercial License, which permits non-commercial use, distribution, and reproduction in other forums, provided the original authors and source are credited. 